\title{
Analisis Penyuluhan Perikanan Partisipatif dan Kompetensi Pembudidaya Ikan di Kabupaten Sumedang
}

\author{
[Analysis of Participative Fisheries Extension and Fish Farmers Competency in \\ Sumedang District]
}

\author{
Erlin Rosiah', Soen'an Hadi Poernomo², OD. Soebhakti Hasan ${ }^{3}$ \\ ${ }^{1}$ Progam Pascasarjana Sekolah Tinggi Perikanan Jakarta \\ ${ }^{2}$ Sekolah Tinggi Perikanan Jakarta, Jalan AUP, Jakarta Selatan DKI Jakarta \\ ${ }^{3}$ Sekolah Tinggi Perikanan Jurluhkan Bogor, Jalan Cikaret No Kota Bogor Jawa Barat
}

Diterima: 26 Februari 2018; Disetujui: 31 Maret 2018

\begin{abstract}
Abstrak
Penyuluhan perikanan partisipatif yang melibatkan pembudidaya ikan dalam perencanaan, pelaksanaan dan evaluasi. Kompetensi pembudidaya ikan sebagai taraf keefektivan perilaku (pengetahun, sikap dan keterampilan) dalam teknis budidaya ikan merupakan salah satu output penyuluhan yang dapat diukur capaiannya. Penelitian ini bertujuan untuk menganalisis deskriptif penyuluhan perikanan partisipatif dan kompetensi pembudidaya ikan, serta menganalisis hubungan penyuluhan partisipatif (perencanaaan $\left(X_{1}\right)$, pelaksanaan $\left(X_{2}\right)$ dan evaluasi $\left(X_{3}\right)$ ) dengan kompetensi pembudidaya ikan ( $Y$ ) menggunakan analisis korelasi spearman. Metode penelitian yang digunakan adalah purposive disproportional stratified random sampling terhadap 114 responden pembudidaya ikan. Hasil penelitian: penyuluhan perikanan partisipatif pada tarap co learning dengan model fasilitatif. Kategori sedang pada proses perencanaan dan evaluasi, serta termasuk kategori tinggi pada pelaksanaan. Tingkat kompetensi pembudidaya ikan: 10,53\% sangat baik; $50,88 \%$ baik, 33,29\% sedang dan 2,63\% rendah. Selain itu sangat baik dalam tandatanda induk matang gonad, obat-obatan ikan, dan cara tebar benih; baik dalam cara pencegahan hama dan penyakit ikan serta proses pembesaran ikan; sedang dalam proses pembenihan ikan, merencanakan produksi ikan dan mengkultur pakan alami; serta rendah dalam membuat pakan buatan. Hasil analisis korelasi spearman: variabel $X_{1}$ dengan $Y$ berhubungan kuat, signifikan dan searah, dengan kontribusi $X_{1}$ terhadap $Y$ sebesar 30,58\%; hubungan $X_{2}$ dengan $Y$ cukup kuat signifikan dan searah, dengan kontribusi $X_{2}$ terhadap $Y$ sebesar $46,10 \%$; hubungan $X_{3}$ dengan $Y$ adalah cukup kuat signifikan dan searah, kontribusi $X_{3}$ terhadap $Y$ sebesar 32,26\%.
\end{abstract}

Kata Kunci: kompetensi; pembudidaya ikan; penyuluhan partisipatif; penyuluhan perikanan

\section{Abstract}

Partisipative fisheries extension process involves fish farmers in planning, implementation and evaluation. Fish farmers are main subject in aquaculture who receive benefits from extension process. Fish farmer competency is behavior effectiveness level (knowledge, attitude, and skill). This research purposed to analysis the competency of fish farmers; participative fisheries extension process; and correlation between participative fisheries extension process i.e. planning $\left(X_{1}\right)$; implementation $\left(X_{2}\right)$; evaluation $\left(X_{3}\right)$ with fish farmers competency $(Y)$. The method used purposive disporprotional stratified random sampling. The number of sample were 114 fish farmers respondent. Descriptive analysis was used to find out fish farmers competency and participative fisheries extension process. Rank Spearman correlation was used to find out the correlation between participative extension planning $\left(X_{1}\right)$ with fish farmers competency $(Y)$; implementation of participative extension $\left(\mathrm{X}_{2}\right)$ with fish farmers competency $(Y)$; and the evaluation of participative extension $\left(\mathrm{X}_{3}\right)$ fish farmers competency $(\mathrm{Y})$. The result of this research showed participative fisheries extension are co learning with fasilitatif model. Medium in planning and evaluation, high in implementation. fish farmers competency was very good $(10,53 \%)$, good $(50,88 \%)$, medium $(33,29 \%)$, less $(2,63 \%)$. The analysis exhibited correlation $X_{1}$ and $Y$ was medium high and give contribution $30,58 \%$, significant and in the same direction; correlation 
between $\mathrm{X}_{2}$ and $\mathrm{Y}$ was high and give contribution 46,10\%, significant and in the same direction; and correlation between $X_{3}$ and $Y$ was medium high and give contribution $32,26 \%$, significant and in the same direction.

Keywords: competency; fish farmer; participative fextension; fisheries extension

Penulis korespondensi

Erlin Rosiah | erlinrosiah@yahoo.co.id

\section{PENDAHULUAN}

Perikanan sebagai salah satu sektor pembangunan yang berbasis pada pe-manfaatan sumberdaya perikanan dapat dijadikan sebagai pilar keunggulan kom-paratif bangsa dalam pembangunan eko-nomi dan kemakmuran masyarakat. Im-plikasi paradigma pembangunan perika-nan menuntut berbagai perubahan di dalam menyikapi dinamika masyarakat dalam era globalisasi ekonomi. Kabupa-ten Sumedang merupakan salah satu kawasan strategis nasional wilayah cekungan Bandung, sehingga diprioritaskan penataan ruangnya karena mempunyai pengaruh sangat penting secara nasional untuk pertumbuhan ekonomi, lingkungan, ilmu pengetahuan serta sosial budaya. Selain itu sesuai Perda Kabupaten Sumedang No. 2 Tahun 2012 tentang Rencana Tata Ruang dan Rencana Wilayah Kabupaten Sumedang Ta-hun 2011-2031 bahwa Sumedang sebagai kawasan minapolitan.

Berkaitan dengan hal tersebut, masyarakat dituntut untuk dapat memanfaatkan potensi sumberdaya perikanan di daerah sehingga mampu menjadi penggerak ekonomi. Potensi sumberdaya perikanan yang ada akan termanfaatkan optimal apabila didukung oleh berbagai hal, diantaranya penyuluhan perikanan dan sumberdaya pelaku utama perikanan sebagai penerima manfaat penyuluhan perikanan. Penerima manfaat penyuluh-an perikanan di Kabupaten Sumedang secara umum tergabung dalam kelompok pelaku utama perikanan. Berdasarkan informasi dari Dinas Pertanian Peternakan dan Perikanan (Distannakkan 2016), di Kabupaten Sumedang terdapat 397 kelompok pelaku utama perikanan, 70,09\% didominasi oleh kelompok pembudidaya ikan (pokdakan) kelas pemula.

Menurut Nataliningsih (2010), tingginya kelompok pemula merupakan permasalahan dalam penyuluhan di lapa-ngan. Proses penyuluhan yang dilakukan pada kelompok pemula kurang efektif. Padahal penyuluhan ini merupakan fak-tor yang paling mempengaruhi keber-hasilan dan keberlanjutan budidaya pe-rikanan di Kabupaten Sumedang. Seba-gaimana 
menurut Dewi (2014) bahwa faktor yang paling mempengaruhi pro-gram budidaya berkelanjutan di Kabu-paten Sumedang adalah pendampingan serta penyuluhan/ pelatihan yang mampu meningkatkan motivasi pembudidaya ikan. Penyuluhan akan berhasil apabila penerima manfaat dijadikan subjek dan pengambil keputusan dalam pembangunan (Mahbud 2007). Selanjutnya Mahbud (2007) juga menyatakan bahwa dalam rangka menciptakan kondisi partisipasi aktif masyarakat pada pembangunan diperlukan adanya penyuluhan partisipatif, dimana penerima manfaat berpartisipasi dalam perencanaan, pelak-sanaan dan evaluasi. Melalui penyuluhan perikanan partisipatif pembudidaya ikan tidak dibiarkan sendirian dalam meng-akses informasi, menganalisis masalah serta menyusun alternatif pemecahan masalah yang dihadapi. Selain itu menurut Hadi (2014), tujuan partisipatif adalah pemberdayaan

INDEPENDENT VARIABLE (X)

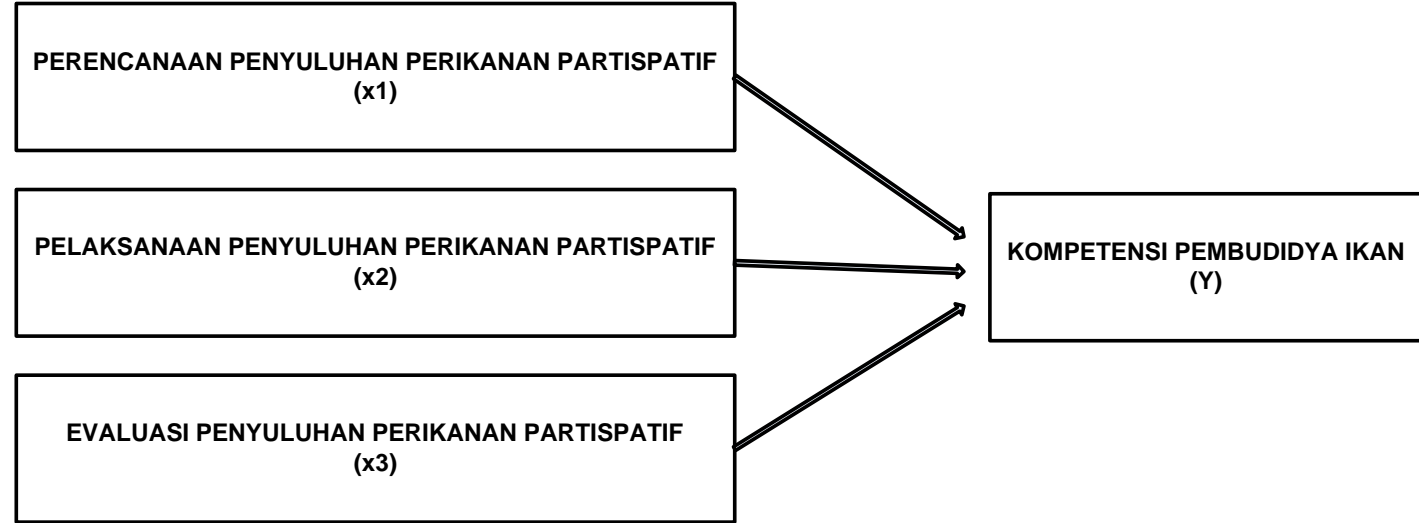

Gambar 1. Kerangka pemikiran penelitian masyarakat yang akan mampu mendukung pembangunan sumber daya manusia secara menyeluruh dan berkelanjutan.

Muchtar (2016) menyatakan bahwa prinsip pembangunan yang bersifat top down masih kental terasa sehingga banyak program yang tidak benar-benar menjadi kebutuhan masyarakat dan tingkat partisipasi rendah. Berbagai program pemerintah berhasil dalam aspek teknis, namun jarang berhasil dalam memberdayakan masyarakat. Pembangunan yang demikian akan menyebabkan ketergantungan masyarakat kepada pemerintah. Selain itu beberapa kajian mengemukakan bahwa pemberdayaan masyarakat belum didukung oleh fungsi penyuluhan efektif (Fatchiya 2010, Sjafari 2010). Kustiari at al. (2012), juga menyatakan semakin efektif penyuluhan dengan fokus keberfungsian penyuluhan partisipatif akan meningkatkan produktivitas pembudidaya. Disamping DEPENDENT VARIABLE (Y) 
itu, Pujiastuti (2014) mengemukakan bahwa pelaku u-tama perikanan dihadapkan pada per-saingan global dan dituntut untuk me-miliki daya saing dan nilai tambah.

\section{Kerangka Pemikiran}

Hipotesis yang dapat dirumuskan:

1. Ho : Tidak ada hubungan yang signifikan

antara perencanaan penyuluhan perikanan partisipatif $\left(\mathrm{X}_{1}\right)$ dengan kompetensi pembudidaya ikan (Y)

$\mathrm{H}_{1}$ : Ada hubungan yang signifikan antara

perencanaan penyuluhan perikanan partisipatif $\left(\mathrm{X}_{1}\right)$ dengan kompetensi pembudidaya ikan (Y)

2. Ho : Tidak ada hubungan yang signifikan antara pelaksanaan penyuluhan perikanan partisipatif $\left(\mathrm{X}_{2}\right)$ dengan kompetensi pembudidaya ikan $(\mathrm{Y})$

$\mathrm{H}_{1}$ : Ada hubungan yang signifikan antara pelaksanaan penyuluhan partisipatif $\left(\mathrm{X}_{2}\right)$ dengan kompetensi pembudidaya ikan (Y)

3. Ho : Tidak ada hubungan yang signifikan antara evaluasi penyuluhan perikanan

$\begin{array}{rrrr} & \text { partisipatif } \quad\left(\mathrm{X}_{3}\right) & \text { dengan } \\ & \text { kompetensi } & \text { pembudidaya } \\ & \text { ikan }(\mathrm{Y}) & & \\ \mathrm{H}_{1}: & \text { Ada } & & \\ & \text { signifikan abungan } & \text { yang } \\ & \text { penyuluhan } & \text { evaluasi } \\ & \text { partisipatif } & \left(\mathrm{X}_{3}\right) & \text { dengan } \\ & \text { kompetensi } & \text { pembudidaya } \\ & \text { ikan }(\mathrm{Y}) & & \end{array}$

Keberhasilan para pelaku utama merupakan salah satu hasil dari pendampingan penyuluh perikanan. Keterlibatan pembudidaya ikan sejak perencanaan, pelaksanaan serta evaluasi penyuluhan perikanan yang dikenal dengan metode partisipatif, diduga efektif untuk mengubah kompetensi pembudidaya ikan. Keberhasilan pembudidaya ikan salah satunya ditunjukkan oleh peningkatan kompetensi berupa perubahan perilaku (pengetahuan, sikap dan keterampilan). Kompetensi pembudidaya ikan tidak dapat dibentuk secara instan, perlu proses yang disertai partisipasi pembudidaya ikan dalam kegiatan penyuluhan perikanan partisipatif, kompetensi penyuluh perikanan serta kebijakan perikanan yang mendukung iklim usaha budidaya ikan.

Tujuan penelitian ini adalah: (1) Menganalisis penyuluhan perikanan partisipatif; (2) Menganalisis kompetensi pembudidaya ikan; serta (3) Menganalisis hubungan penyuluhan perikanan 
partisipatif dengan kompetensi pembudidaya di Kabupaten Sumedang.

\section{BAHAN DAN METODE}

Penelitian dilaksanakan dari tanggal 2 Januari sampai 3 April Tahun 2017 bertempat di Kabupaten Sumedang, menggunakan mixed method kuantitatif dan kualitatif. Metode pengumpulan data yang digunakan adalah purposive disproportional stratified random sampling terhadap 114 responden pembudidaya ikan air tawar dengan kriteria: tergabung dalam pokdakan dan sudah pernah berpartisipasi dalam kegiatan penyuluhan yang dilakukan oleh penyuluh perikanan PNS; telah berbudidaya ikan lebih dari dua tahun dan telah menjual ikan hasil budidaya secara kontinyu. Teknik pengumpulan data yang digunakan dalam penelitian ini adalah pengisian kuisioner, wawancara, FGD dan observasi lapangan.Teknik analisis deskriptif untuk menganalisis penyuluhan perikanan partisipatif dan kompetensi pembudidaya ikan dan Analisis korelasi spearman untuk menganalisis hubungan penyuluhan perikanan partisipatif terhadap kompetensi pembudidaya ikan.

\section{HASIL DAN PEMBAHASAN}

Kabupaten Sumedang, Provinsi Ja-wa Barat secara administrasi terletak pada posisi 6 ${ }^{\circ} 40^{\prime}-7^{\circ} 83^{\prime}$ Lintang Selatan dan 107014'-108 $21^{\prime}$ 'Bujur Timur dengan luas wilayah $155,20 \mathrm{~km}^{2}$. Jarak an- tar batas wilayah dari utara-selatan sejauh $51 \mathrm{~km}$ dan dari arah barat-timur sejauh $53 \mathrm{~km}$, terdiri dari 26 kecamatan, 270 desa dan 7 kelurahan. Sumedang di sebelah timur berbatasan dengan Kabupaten Majalengka; barat Kabupaten Bandung; selatan Kabupaten Garut;dan utara Kabupaten Indramayu dan Subang. (BPS Kabupaten Sumedang, 2016)

Penyuluhan perikanan di Kabupaten Sumedang saat ini merupakan salah satu tugas pokok Dinas Perikanan dan Peternakan Kabupaten Sumedang. Sebanyak 9 penyuluh perikanan PNS yang membina 397 kelompok pelaku utama perikanan di Kabupaten Sumedang. Dari jumlah tersebut sebanyak 314 kelompok merupakan kelompok pembudidaya ikan. Kegiatan dan proses penyuluhan yang dilakukan oleh penyuluh perikanan PNS terhadap pembudidaya ikan selalu mengupayakan penyuluhan perikanan partisipatif.

Karakteristik penyuluh perikanan di Kabupaten Sumedang menunjang kegiatan penyuluhan perikanan di Kabupaten Sumedang. Dari 9 orang Penyuluh Perikanan PNS Kabupaten Sumedang, lima orang laki-laki $(55,56 \%)$ dan empat orang perempuan $(44,44 \%)$. Kisaran usia penyuluh perikanan, sebanyak tiga orang $(33,33 \%)$ berada pada rentang usia 31 40 tahun, satu orang $(11,11 \%)$ penyuluh berusia 41-50 tahun dan 5 orang penyu- 
luh $(55,56 \%)$ berada pada rentang usia 51-60 tahun. Tingkat pendidikan penyuluh perikanan sebanyak dua orang penyuluh $(22,22 \%)$ pada jenjang SLTA dan tujuh orang penyuluh $(77,78 \%)$ per-nah mengenyam pendidikan di per-guruan tinggi. Selain itu, penyuluh perikanan Sumedang berpengalaman menyuluh. Dari data menunjukkan satu orang penyuluh (11,11\%) berpenga-laman menyuluh kurang dari lima tahun. Sebanyak dua orang penyuluh $(22,22 \%)$ berpengalaman menyuluh 5-10 tahun dan sebanyak enam orang penyuluh $(66,67 \%)$ berpengalaman menyuluh lebih dari 10 tahun.

Penyuluhan partisipatif terhadap pembudidaya ikan di Kabupaten Sumedang disesuaikan situasi, kondisi dan kebutuhan para pembudidaya ikan. Peran penyuluh perikanan salah satunya dalam memberdayakan pembudidaya ikan sup-aya memiliki kompetensi teknis budi-daya ikan. Melalui kegiatan penyuluhan perikanan, pembudidaya ikan mendapat-kan pengetahuan dan keterampilan. Pe-nyuluhan menstimulasi timbulnya kebu-tuhan informasi teknik budidaya ikan melalui pengembangan dan pengorga-nisasian kelompok serta membimbing pembudidaya memiliki kepedulian pada pelestarian lingkungan. Ketepatan nilai-nilai yang dikembangkan dalam penyu-luhan perikanan untuk mengembangkan kompetensi teknis pembudidaya ikan menyesuaikan dengan kearifan lokal dan menjalin kerja sama dengan stakeholder seperti tokoh masyarakat, tokoh agama, tokoh adat dan beberapa instansi dan kelembagaan yang terkait dengan ma-syarakat. Perencanaan program penyu-luhan perikanan ditentukan berdasarkan aspirasi pembudidaya mengenai prioritas masalah dan kesesuaian penerima manfaat penyuluhan perikanan. Pembudidaya diberikan kesempatan untuk berperan dalam kegiatan penyuluhan. Pembudidaya mampu membuat penilaian atas kegiatan penyuluhan yang telah dilaksanakan. Selain itu pembudidaya berkesempatan memperoleh manfaat lainnya.

Apabila mengacu pada bentuk partisipasi menurut Syahyuti (2006), penyuluhan perikanan partisipatif di Kabupaten Sumedang termasuk bentuk co learning, peran masyarakat (penerima manfaat) sebagai partners. Masyarakat pembudidaya ikan dan pihak luar (penyuluh perikanan) saling membagi pengetahuannya, untuk memperoleh saling pengertian, dan bekerja sama untuk merencanakan aksi, sementara pihak luar (penyuluh perikanan) hanya memfasilitasi. Selain itu model penyuluhan partisipatif yang berkembang di Kabupaten Sumedang saat ini adalah model fasilitasi dengan tujuan pemberdayaan dan kemandirian. Sumber informasi yang digunakan pengetahuan lokal dan 
inovasi. Peran penyuluh sebagai fasilitator, peran pembudidaya belajar sambil bekerja dan belajar dari satu pembudidaya ke pembudidaya lainnya. Peranan pembudidaya aktif memecahkan masalah, terlibat proses dan sasaran ke- lompok dan organisasi-organisasi, interaksi dan jaringan.

\section{Karakteristik Responden}

Responden pembudidaya ikan disajikan pada Tabel 1., mempengaruhi

Tabel 1. Karakteristik responden pembudidaya ikan

\begin{tabular}{|c|c|c|c|c|}
\hline No. & & Karakteristik & Jumlah & $\%$ \\
\hline \multirow[t]{2}{*}{1} & \multirow[t]{2}{*}{ Jenis Kelamin } & Laki-laki & 105 & 92,11 \\
\hline & & Perempuan & 9 & 7,89 \\
\hline \multirow[t]{2}{*}{2} & \multirow[t]{2}{*}{ Usia } & 20-54 tahun & 69 & 60,53 \\
\hline & & $>54$ tahun & 45 & 39,47 \\
\hline \multirow[t]{5}{*}{3} & \multirow[t]{5}{*}{ Pendidikan } & Tidak Tamat SD & 1 & 0,88 \\
\hline & & $\mathrm{SD} / \mathrm{SR}$ & 37 & 32,46 \\
\hline & & SLTP & 22 & 19,30 \\
\hline & & SLTA & 36 & 31,58 \\
\hline & & Perguruan Tinggi & 18 & 15,79 \\
\hline \multirow[t]{3}{*}{4} & \multirow[t]{3}{*}{ Pengalaman } & $2<$ Pengalaman $<5$ tahun & 49 & 42,98 \\
\hline & & 5 - 10 tahun & 51 & 44,74 \\
\hline & & $>10$ tahun & 14 & 12,28 \\
\hline \multirow[t]{3}{*}{5} & \multirow{3}{*}{$\begin{array}{l}\text { Keikutsertaan dalam } \\
\text { pelatihan }\end{array}$} & Belum pernah & 36 & 31,58 \\
\hline & & $1-5$ kali & 66 & 57,89 \\
\hline & & $>5$ kali & 12 & 10,53 \\
\hline \multirow[t]{3}{*}{6} & \multirow{3}{*}{$\begin{array}{l}\text { Partisipasi dlm } \\
\text { penyuluhan }\end{array}$} & $<5$ kali & 20 & 17,54 \\
\hline & & 5-10 kali & 32 & 28,07 \\
\hline & & >10 kali & 62 & 54,39 \\
\hline \multirow[t]{6}{*}{7} & \multirow{6}{*}{$\begin{array}{l}\text { Komoditas yang } \\
\text { dibudidayakan }\end{array}$} & Nila dan mas & 31 & 27,19 \\
\hline & & Nila & 29 & 25,44 \\
\hline & & Mas & 25 & 21,93 \\
\hline & & Lele & 19 & 16,67 \\
\hline & & Gurame & 7 & 6,14 \\
\hline & & Ikan Hias & 3 & 2,63 \\
\hline \multirow[t]{3}{*}{8} & \multirow{3}{*}{$\begin{array}{l}\text { Kegiatan budidaya } \\
\text { yang digeluti }\end{array}$} & Pembenihan & 70 & 61,40 \\
\hline & & Pembesaran & 22 & 19,30 \\
\hline & & Pembenihan sampai pembesaran & 22 & 19,30 \\
\hline
\end{tabular}


Tabel 2. Keterlibatan responden dalam penyuluhan perikanan partisipatif

\begin{tabular}{lcccccc}
\hline \multirow{2}{*}{$\begin{array}{c}\text { Kategori nilai } \\
\text { skor }\end{array}$} & \multicolumn{2}{c}{ Perencanaan } & \multicolumn{2}{c}{ Pelaksanaan } & \multicolumn{2}{c}{ Evaluasi } \\
\cline { 2 - 7 } & Jumlah & $\%$ & Jumlah & $\%$ & Jumlah & $\%$ \\
\hline Sangat tinggi & 4 & $3,51 \%$ & 10 & $8,77 \%$ & 7 & $6,03 \%$ \\
\hline Tinggi & 20 & $17,54 \%$ & 40 & $35,09 \%$ & 21 & $18,10 \%$ \\
\hline Sedang & 38 & $33,33 \%$ & 57 & $50,00 \%$ & 59 & $50,86 \%$ \\
\hline Rendah & 52 & $45,61 \%$ & 7 & $6,14 \%$ & 27 & $23,28 \%$ \\
\hline Sangat rendah & 0 & - & 0 & $0,00 \%$ & 2 & $1,72 \%$ \\
\hline & 114 & $100,00 \%$ & 114 & $100,00 \%$ & 116 & $100,00 \%$ \\
\hline
\end{tabular}

kompetensi responden. Hal ini sesuai pendapat Safiudin (2008) yang menyatakan bahwa kompetensi pembudidaya berhubungan sangat nyata dengan pendidikan formal, usia, jumlah anggota keluarga, pendapatan, penggunaan media, pengalaman, motivasi dan modal.

\section{Penyuluhan Perikanan Partisipatif}

Responden yang terlibat dalam perencanaan, pelaksanaan dan evaluasi penyuluhan perikanan, pengetahuan, sikap dan keterampilannya (kompetensinya) lebih baik dibandingkan dengan responden yang tidak terlibat. Responden menyatakan ikut serta peren-canaan, pelaksanaan, dan evaluasi pe-nyuluhan perikanan, manfaatnya termo-tivasi dalam berbudidaya.

Sejak dini dapat terdeteksi apabila ada ciri-ciri ikan sakit dan hama pun dapat teratasi. Selain itu dapat mengetahui potensi yang dimiliki, sehingga dapat menentukan berapa banyak benih yang dapat ditebar, dapat direncanakan untuk menghasilkan produksi sesuai keinginan. Keterlibatan dalam perencanaan, pelaksanaan dan evaluasi dapat mengatasi ke-jenuhan. Pada saat inilah dapat berkumpul, bertukar pikiran, sambil cerita dan hiburan.

\section{Perencanaan Penyuluhan Perikanan} Partisipatif

Pembudidaya tidak terlalu peduli dalam merencanakan kegiatan penyuluh-an, karena terkadang apa yang direnca-nakan tidak dilaksanakan karena peru-bahan kebijakan akibat pergantian ke-pemimpinan akan, terkadang hanya pe-ngurus atau ketua kelompok yang terlibat dalam perencanan. Pembudidaya berharap, penyuluh agar menanyakan terlebih dahulu kepada mereka mengenai materi dan metode yang diinginkan responden. 
Tabel 3. Kriteria interpretasi skor responden dalam perencanaan penyuluhan perikanan partisipatif

\begin{tabular}{lcccc}
\hline \multicolumn{1}{c}{ Perencanaan Penyuluhan Partisipatif } & Jumlah & $\begin{array}{c}\text { Skor } \\
\text { Maksimum }\end{array}$ & Prosentase & $\begin{array}{c}\text { Tingkat } \\
\text { Partisipatif }\end{array}$ \\
\hline Merencanakan kegiatan penyuluhan & 252 & 570 & $44,21 \%$ & sedang \\
\hline Merencanakan materi dan metode penyuluhan & 349 & 570 & $61,23 \%$ & tinggi \\
\hline Melakukan Identifikasi potensi usaha budidaya & 348 & 570 & $61,05 \%$ & tinggi \\
\hline Melakukan Identifikasi permasalahan budidaya & 359 & 570 & $62,98 \%$ & tinggi \\
\hline Rata-rata & & & $57,37 \%$ & sedang \\
\hline
\end{tabular}

Tabel 4. Kriteria interpretasi skor responden dalam pelaksanaan penyuluhan perikanan partisipatif

\begin{tabular}{lcccc}
\hline \multicolumn{1}{c}{ Pelaksanaan Penyuluhan Partisipatif } & Jumlah & $\begin{array}{c}\text { Skor } \\
\text { Maksimum }\end{array}$ & $\begin{array}{c}\text { Prosentas } \\
\text { e }\end{array}$ & $\begin{array}{c}\text { Tingkat } \\
\text { Partisipatif }\end{array}$ \\
\hline Melaksanakan kegiatan penyuluhan & 542 & 570 & $95,09 \%$ & $\begin{array}{c}\text { Sangat } \\
\text { tinggi }\end{array}$ \\
\hline Materi \& metode penyuluhan sesuai kebutuhan & 263 & 570 & $46,41 \%$ & sedang \\
\hline Memanfaatkan potensi usaha budidaya & 277 & 570 & $48,60 \%$ & sedang \\
\hline $\begin{array}{l}\text { Ikut serta dalam penyuluhan teknis budidaya } \\
\text { ikan }\end{array}$ & 343 & 570 & $76,14 \%$ & tinggi \\
\hline Rata-rata & & & $66,49 \%$ & tinggi \\
\hline
\end{tabular}

\section{Pelaksanaan Penyuluhan Partisipatif}

Berdasarkan observasi lapangan, responden yang tidak pernah terlibat dalam pelaksanaan penyuluhan perikanan memperlihatkan kompetensi yang kurang baik. Responden menyatakan bahwa penyuluh perikanan yang sering datang berkunjung bersikap ramah, sopan serta mampu menyesuaikan dengan adat kebiasaan yang ada. Sebagai contoh adanya kepercayaan "larangan bulan", yang berarti ada suatu hari yang dilarang untuk memulai aktivitas dan bepergian untuk mencari nafkah. Apabila tetap saja dilaksanakan kegiatan penyuluhan, maka tingkat kehadiran akan menurun bahkan tidak hadir sama sekali. Hal ini sejalan dengan pendapat Safrida (2015) mengenai kemampuan adaptasi penyuluh dapat diterima masyarakat. Hasil observasi menunjukkan bahwa responden yang aktif terlibat dalam pelaksanaan penyuluhan perikanan, akan selau termotivasi untuk melakukan apa yang dianjurkan oleh penyuluh perikanan sehingga kompetensinya semakin baik.

Tingkat partisipatif rata-rata responden dalam memanfaatkan potensi budidaya termasuk kategori sedang, 
Tabel 5. Kriteria interpretasi skor responden dalam evaluasi penyuluhan perikanan partisipatif

\begin{tabular}{lcccc}
\hline \multicolumn{1}{c}{ Evaluasi Penyuluhan Partisipatif } & Jumlah & $\begin{array}{c}\text { Skor } \\
\text { Maksimum }\end{array}$ & Prosentase & $\begin{array}{c}\text { Tingkat } \\
\text { Partisipatif }\end{array}$ \\
\hline Mengevaluasi kegiatan penyuluhan perikanan & 224 & 570 & $39,30 \%$ & rendah \\
\hline Mengevaluasi materi \& metode penyuluhan & 345 & 570 & $60,53 \%$ & sedang \\
\hline $\begin{array}{l}\text { Mengevaluasi pemanfaatan potensi usaha } \\
\text { budidaya }\end{array}$ & 422 & 570 & $74,04 \%$ & tinggi \\
\hline Menerapkan teknis budidaya ikan sesuai anjuran & 393 & 570 & $68,95 \%$ & tinggi \\
\hline Rata-rata & & & $60,70 \%$ & sedang \\
\hline
\end{tabular}

tetapi berkategori rendah dalam memanfaatkan potensi budidaya, produktivitas masih tergolong rendah, apalagi pada kegiatan budidaya ikan hias, belum produksi secara masal.

- Materi penyuluhan terkadang tidak sesuai kebutuhan, sebagai contoh pada kegiatan bantuan benih, materi mengenai benih ikan (benih berkualitas, cara tebar benih sudah disampaikan secara ceramah tanpa praktik, sebelum bentuan benih ikan sampai di pembudidaya.

\section{Evaluasi Penyuluhan Partisipatif}

Evaluasi penyuluhan ini terkadang tidak pernah dilakukan bersama-sama penyuluh dan pembudidaya. Ada yang pernah melakukan evalusi ini secara bersama-sama. Belum semua pembudidaya terlibat dalam evaluasi penyuluhan perikanan partisipatif. Pembudidaya tidak berparisipasi dalam evaluasi penyuluhan perikanan, saat perenacanaan pun tidak turut serta. Responden menyatakan un- tuk apa mengevaluasi penyuluhan perikanan, karena tidak ikut serta dalam perencanaa evaluasi penyuluan perikanan partisipatif.

Hal tersebut menunjukkan bahwa pada evaluasi penyuluhan perikanan par-tisipatif secara kontinum belum optimal. Responden ada yang menyatakan bahwa, dalam evaluasi penyuluhan perikanan ini, terkadang tidak ikut serta dan tidak terlibat karena pada saat perencanaan pun tidak terlibat, tapi pada pelaksanaan penyuluhan saya selalu hadir.

\section{Kompetensi Responden}

Kompetensi yang diamati pada penelitian ini fokus pada kompetensi teknis budidaya ikan air tawar yang dilakukan oleh responden. Kompetensi ini terkait dengan kemampuan pembudidaya ikan dalam melakukan suatu pekerjaan. Kompetensi merupakan deskripsi keefektivan perilaku (pengetahuan, sikap dan keterampilan) dalam melakukan kegiatan 
budidaya ikan. Kegiatan budidaya ikan yang dilakukan responden terdiri dari kegiatan pembenihan (70 orang), pembesaran (22 orang) serta pembenihan sampai pembesaran ikan (22 orang).

Secara umum pengetahuan sikap dan keterampilan lebih setengahnya dari jumlah responden pada kegitan pembenihan serta kegiatan pembenihan sam-pai pembesaran berkategori sangat baik dan baik. Hal ini dapat terhlihat dari hasil observation checklist produksi benih rata-rata sudah sesuai dari SNI.

Kompetensi Responden pada Kegiatan Pembenihan Ikan

Responden sangat faham mengenai obat-batan ikan yang dilarang. Biasanya apabila melihat tanda-tanda ikan sakit, segera memberikan ramuan obat dari ba-han-bahan alami. Menurut responden, cara utama dalam mengendalikan hama dan penyakit ikan

Tabel 6. Kompetensi responden pembudidaya sesuai kriteria

\begin{tabular}{lcccccccc}
\hline \multirow{2}{*}{$\begin{array}{c}\text { Tk.Kompetensi } \\
\text { Responden }\end{array}$} & \multicolumn{2}{c}{ Pembenihan } & \multicolumn{2}{c}{ Pembesaran } & \multicolumn{2}{c}{$\begin{array}{c}\text { Pembenihan } \\
\text { sampai } \\
\text { pembesaran }\end{array}$} & \multicolumn{2}{c}{ Total } \\
\cline { 2 - 11 } & Jumlah & $\%$ & Jumlah & $\%$ & Jumlah & $\%$ & Jumlah & $\%$ \\
\hline Sangat baik & 11 & $9,66 \%$ & - & - & 1 & $0,88 \%$ & 12 & $10,53 \%$ \\
\hline Baik & 44 & $38,60 \%$ & - & - & 14 & $12,28 \%$ & 58 & $50,88 \%$ \\
\hline Sedang & 15 & $13,16 \%$ & 18 & $15,79 \%$ & 4 & $3,51 \%$ & 37 & $32,46 \%$ \\
\hline Rendah & - & - & 1 & $0,88 \%$ & 2 & $1,75 \%$ & 3 & $2,63 \%$ \\
\hline Sangat rendah & - & - & 3 & $2,63 \%$ & 1 & $0,88 \%$ & 4 & $3,51 \%$ \\
\hline
\end{tabular}

Tabel 7. Kriteria interpretasi skor kompetensi responden pada kegiatan pembenihan

\begin{tabular}{lcccc}
\hline \multicolumn{1}{c}{$\begin{array}{c}\text { Indikator Kompetensi } \\
\text { Pembenihan Ikan }\end{array}$} & Jumlah & $\begin{array}{c}\text { Skor } \\
\text { Maksimu } \\
\mathbf{m}\end{array}$ & $\begin{array}{c}\text { Prosentas } \\
\mathbf{e}\end{array}$ & $\begin{array}{c}\text { Tingkat } \\
\text { Kompetensi }\end{array}$ \\
\hline A. Melakukan Pembenihan Ikan & 202 & 350 & $57,71 \%$ & sedang \\
\hline$\quad$ Proses pembenihan Ikan & 326 & 350 & $93,14 \%$ & sangatbaik \\
\hline Tanda-tanda Induk Matang Gonad & & & & \\
\hline B. Melakukan Pengendalian Hama \& Penyakit Ikan & 289 & 350 & $82,57 \%$ & sangatbaik \\
\hline Obat-obatan ikan & 273 & 350 & $78,00 \%$ & tinggi \\
\hline$\quad$ Cara pencegahan hama dan penyakit lkan & & & & \\
\hline C. Mengkultur Pakan Alami & 190 & 350 & $54,29 \%$ & sedang \\
\hline$\quad$ Mengkultur Pakan alami & & & $73,14 \%$ & baik \\
\hline Rata-rata
\end{tabular}


Tabel 8. Kriteria interpretasi skor kompetensi responden pada kegiatan pembesaran ikan

\begin{tabular}{lcccc}
\hline \multicolumn{1}{c}{$\begin{array}{c}\text { Indikator Kompetensi } \\
\text { Pembesaran Ikan }\end{array}$} & Jumlah & $\begin{array}{c}\text { Skor } \\
\text { Maksimum }\end{array}$ & Prosentase & $\begin{array}{c}\text { Tingkat } \\
\text { Kompetensi }\end{array}$ \\
\hline A. Melakukan Pembesaran Ikan & & & & \\
\hline Proses pembesaran Ikan & 90 & 110 & $81,82 \%$ & Sangat baik \\
\hline Cara tebar benih & 83 & 110 & $75,45 \%$ & tinggi \\
\hline B. Membuat Pakan Buatan & & & & \\
\hline$\quad$ Membuat pakan buatan & 30 & 110 & $27,27 \%$ & rendah \\
\hline C. Merencanakan Proses Produksi & & & & \\
\hline$\quad$ Merencanakan Produksi lkan & 47 & 110 & $42,73 \%$ & sedang \\
\hline Rata-rata & & & $56,82 \%$ & sedang \\
\hline
\end{tabular}

selain melakukan teknologi sesuai anjuran, adalah ketika berbudidaya ikan baik wadah, media air, maupun ikan yang dibudidayakan "ku-duremen katingali ku bulu bitis" (sering terlihat oleh bulu betis) yang bermakna wadah, media air, maupun ikan yang di-budidayakan setiap hari harus dipantau dan diamati, sehingga hama akan mudah terdeteksi dan penyakit dapat dicegah.

\section{Kompetensi Responden pada Kegiatan Pembesaran Ikan}

Berdasarkan hasil wawancara, responden melakukan teknik pembesaran ikan sesuai dengan anjuran penyuluh perikanan. Salah satunya mengoptimalkan padat tebar ikan, dengan jumlah tebar benih ikan minimal disesuaikan dengan luas kolam yang dimiliki.

Pada pembesaran ikan hias tidak melakukan tebar benih secara banyak, dan lebih sedikit daripada tebar benih ikan konsumsi. Lebih mengutamakan kualitas ikan hias yang dihasilkan. Ratarata pembudidaya melakukan teknik aklimatisai sebelum tebar benih.

Menurut responden teknologi proses pembesaran ikan dilakukan sesuai anjuran penyuluh perikanan. Termasuk teknologi cara tebar benih dilakukan melalui tahapan aklimatisasi benih. Kompetensi responden dalam merencanakan produksi tergolong sedang. Hasil observasi menunjukkan responden pada kegiatan pembenihan tidak mempunyai rencana produksi tertulis dan memerlukan bimbingan dalam merencanakan produksi ikan. Selain itu responden belum secara kontinu menuliskan perencanaan produksi dan hasil produksi belum optimal. Kompetensi responden dalam membuat pakan buatan termasuk rendah. Responden belum tahu mengenai cara dan formulasi 
Tabel 9. Kriteria interpretasi skor kompetensi responden pada kegiatan pembenihan sampai pembesaran ikan

\begin{tabular}{|c|c|c|c|c|}
\hline $\begin{array}{c}\text { Indikator Kompetensi Kegiatan Pembenihan } \\
\text { sampai Pembesaran }\end{array}$ & Jumlah & $\begin{array}{c}\text { Skor } \\
\text { Maksimu } \\
\text { m }\end{array}$ & $\begin{array}{l}\text { Prosentas } \\
\text { e }\end{array}$ & $\begin{array}{l}\text { Tingkat } \\
\text { Kompetensi }\end{array}$ \\
\hline \multicolumn{5}{|l|}{ A. Melakukan Pembenihan lkan } \\
\hline Proses pembenihan Ikan & 71 & 110 & $64,55 \%$ & baik \\
\hline Tanda-tanda Induk Matang Gonad & 97 & 110 & $88,18 \%$ & sangat baik \\
\hline \multicolumn{5}{|l|}{ B. Melakukan Pengendalian Hama \& Penyakit lkan } \\
\hline Obat-obatan ikan & 93 & 110 & $84,55 \%$ & sangat baik \\
\hline Cara pencegahan hama dan penyakit Ikan & 97 & 110 & $88,18 \%$ & sangatbaik \\
\hline \multicolumn{5}{|l|}{ C. Mengkultur Pakan Alami } \\
\hline Mengkultur Pakan alami & 46 & 110 & $41,82 \%$ & sedang \\
\hline \multicolumn{5}{|l|}{ D. Melakukan Pembesaran Ikan } \\
\hline Proses pembesaran Ikan & 81 & 110 & $73,64 \%$ & baik \\
\hline Cara tebar benih & 101 & 110 & $91,82 \%$ & Sangat baik \\
\hline \multicolumn{5}{|l|}{ E. Membuat Pakan Buatan } \\
\hline Membuat pakan buatan & 42 & 110 & $38,18 \%$ & rendah \\
\hline \multicolumn{5}{|l|}{ F. Merencanakan Proses Produksi } \\
\hline Merencanakan Produksi lkan & 51 & 110 & $46,36 \%$ & sedang \\
\hline Rata-rata & & & $68,59 \%$ & tinggi \\
\hline
\end{tabular}

pakan bua-tan. Ada responden yang sudah pernah membuat pakan buatan, tetapi pakan tersebut belum secara optimal ber-pengaruh terhadap percepatan partum-buhan ikan. Akan tetapi responden be-lum terbiasa bahkan belum tau cara dan formulasi dalam membuat pakan buatan. Responden mengharapkan penyuluhan/ pelatihan yang disertai praktik menentukan dan membuat formulasi pakan yang dapat mempercepat pertumbuhan.
Kompetensi Responden pada Kegiatan Pembenihan Sampai dengan Pembesaran

Responden telah melakukan hal tersebut sesuai anjuran penyuluh perikanan dan hal ini telah dilakukan selama dua tahun. Menurut responden dengan melakukan hal tersebut, dapat mengurangi kematian benih dan produksi semakin baik dan tidak ada keluhan lagi dari pelanggan.

Terdapat kendala yang masih belum bisa diatasi dengan maksimal yaitu banyaknya kematian larva, terutama pada budidaya ikan lele. Pembudidaya mengharapkan bimbingan mengenai 
pengelolaan air budidaya agar menghasilkan benih lele yang lebih banyak.

Kompetensi responden dalam merencanakan produksi termasuk sedang. Responden merencanakan produksi secara sederhana salah satunya dengan melingkari tanggal di kalender dan menuliskan kegiatan apa yang dilakukan. Merencanakan produksi ini secara umum belum dilakukan secara kontinyu dan tertulis. Ada pula responden yang merencanakan produksi ini secara bersama-sama pembudidaya lain yang tergabung di kelompok. Salah satunya membuat rencana usaha anggota (RUA), kemudian membuat rencana kelompok (RUK) dan membuat rencana definitif kebutuhan ke-lompok (RDKK). Pada saat pembuatan renaca ini difasilitasi oleh penyuluh pe-rikanan. Berdasarkan informasi dari res-ponden belum semua pembudidaya ikan di Kabupaten Sumedang mampu me-rencanakan produksi, sehingga perlu bimbingan dan pendamping dalam merencanakan produksi. Tingkat kompe-tensi membuat pakan buatan termasuk rendah. Kondisi ini sama dengan pada kegiatan pembesaran ikan. Membuat pa-kan buatan belum dilakukan, selain se-cara teori belum memahami cara pembuatannya, responden ini tidak mau repot memebuat pakan buatan.

Lebih baik menggunakan pakan buatan yang sudah jelas kadar protein dan kandungan lainnya, hanya tinggal menambahkan probiotik, supaya pakan lebih mudah dicerna oleh ikan.

\section{Hubungan Penyuluhan Perikanan Partisipatif dengan Kompetensi Responden}

Hasil perhitungan menunjukkan bahwa hubungan perencanaan dan evaluasi penyuluhan perikanan partisipatif dengan kompetensi adalah cukup kuat, searah dan signifikan. Selain itu pelaksanaan penyuluhan perikanan partisipatif menunjukkan hubungan kuat, searah dan signifikan. Penyuluhan perikanan parti-sipatif memberikan kontribusi terhadap kompetensi pembudidaya ikan: peren-canaan berkontribusi sebesar $30,58 \%$, pelaksanaan berkontribusi

Tabel 10. Hubungan Penyuluhan Perikanan Partisipatif dengan Kompetensi Responden

\begin{tabular}{clccccl}
\hline No. & $\begin{array}{c}\text { Penyuluhan } \\
\text { Partisipatif }\end{array}$ & $\boldsymbol{\rho}$ spearman & $\mathbf{Z}_{\text {hitung }}$ & $\mathbf{Z}_{\text {tabel }}$ & KP & Interpretasi hubungan \\
\hline 1 & Perencanaan & 0,553 & 7,17 & 1,96 & 30.58 & cukup kuat, searah, signifikan \\
\hline 2 & Pelaksanaan & 0,679 & 2,82 & 1,96 & 46.10 & kuat, searah, signifikan \\
\hline 3 & Evaluasi & 0,568 & 5,15 & 1,96 & 32,26 & cukup kuat, searah, signifikan \\
\hline
\end{tabular}


sebesar 46,10\% dan evaluasi berkontribusi se-besar 32,26\%.

\section{SIMPULAN DAN SARAN}

\section{Simpulan}

1. Penyuluhan perikanan partisipatif di Kabupaten Sumedang termasuk bentuk co learning, peran masyarakat (penerima manfaat) sebagai partners dengan model fasilitatif. Intrepretasi dari komponen proses penyuluhan perikanan partisipatif di Kabupaten Sumedang adalah sebagai berikut: pada perencanaan dan evaluasi penyuluhan partipatif termasuk kategori sedang, serta pada pelaksanaan penyuluhan partisipatif termasuk kategori tinggi;

2. Kompetensi pembudidaya ikan di Kabupaten Sumedang menunjukkan pada tarap keefektifan pengetahun, sikap dan keterampilan dalam kegiatan budidaya ikan sebagai berikut: sangat baik sebanyak 10,53\% pembudidaya; baik sebanyak 50,88\% pembudidaya; sedang sebanyak $32,46 \%$ pembudidaya; rendah sebanyak 2,63\% pembudidaya. Intrepretasi dari komponen kompetensi pembudidaya ikan di Kabupaten Sumedang adalah sebagai berikut: sangat baik dalam tanda-tanda induk matang gonad, obat-obatan ikan, dan cara tebar benih; baik dalam ca-ra pencegahan penyakit ikan dan proses pembesaran ikan; sedang da-lam pembenihan ikan, merencanakan produksi ikan, meng-kultur pakan alami; rendah dalam membuat pakan buatan;

3. Hubungan korelasional antara penyuluhan perikanan partisipatif dan kompetensi pembudidaya ikan di Kabupaten Sumedang adalah sebagai berikut: Ada hubungan cukup kuat, signifikan dan searah antara perencanaan penyuluhan perikanan partisipatif dengan kompetensi pembudidaya ikan (nilai koefisien korelasi sebesar 0,553) dan mem-berikan kontribusi terhadap kompe-tensi pembudidaya ikan sebesar $30,58 \%$; Ada hubungan signifikan, kuat dan searah antara pelaksanaan penyuluhan perikanan partisipatif dengan kompetensi pembudidaya ikan (nilai koefisien korelasi sebesar 0,679) memberikan kontribusi terhadap kompetensi pembudidaya ikan sebesar 46,10\%; Ada hubungan signifikan, cukup kuat dan searah antara evaluasi penyuluhan perikanan partisipatif dengan kom-petensi pembudidaya ikan dengan nilai koefisien korelasi sebesar 0,568 serta berkontribusi terhadap kompetensi pembudidaya ikan sebe-sar $32,26 \%$. 


\section{Saran}

1. Dalam penyuluhan perikanan terhadap pembudidaya ikan di Kabupaten Sumedang perlu ditingkatkan metode dan materi penyuluhan mengenai mengkultur pakan alami, membuat pakan buatan dan merencanakan proses produksi ikan;

2. Perlu ditingkatkan keterlibatan pembudidaya ikan dalam dalam merencanakan kegiatan penyuluhan perikanan, materi dan metode sesuai dengan kebutuhan pembudidaya ikan, memanfaatkan potensi usaha budidaya serta mengevaluasi kegiatan penyuluhan perikanan dengan cara memberikan reward;

3. Bagi penyuluh perikanan Kabupaten Sumedang agar senantiasa menerapkan prinsip-prinsip penyuluhan perikanan partisipatif dalam membina pembudidaya ikan dengan cara meningkatkan intensitas kunjungan penyuluhan;

4. Bagi pemangku kebijakan, perlu adanya kebijakan mengenai program pengembangan kompetensi pembudidaya ikan yang dilaksanakan secara konsisten dan berkelanjutan yang dalam perencanaan, pelaksanaan dan evaluasinya dilakukan secara partisipatif sesuai dengan kebutuhan dan kondisi pembudidaya ikan;
5. Perlu dilakukan penelitian lanjutan mengenai bagaimana hubungan penyuluhan perikanan partisipatif (perencanaan, pelaksanaan dan evaluasi) variabel independen secara bersama-sama dengan kompetensi pembudidaya ikan dan pengaruhnya terhadap pendapatan.

\section{DAFTAR PUSTAKA}

Dewi S. 2014. Analisis sustainable aquaculture for food security and poverty reduction (SAFVER) di Kabupaten Sumedang Provinsi Jawa Barat [Tesis]. Bandung: Universitas Padjadjaran Program Pascasarjana Magister IImu Lingkungan. Halaman 2-89

[Disnakkan] Dinas Peternakan dan Perikanan Kabupaten Sumedang. 2014. Laporan Akhir Penyusunan Kajian Masterplan Kawasan Minapolitan Kabupaten Sumedang

[Distannakan] Dinas Pertanian Peternakan dan Perikanan Kabupaten Sumedang. 2016. Programa Penyuluhan Perikanan. Halaman 431

Fatchiya A. 2010. Pola pengembangan kapasitas pembudidaya ikan kolam air tawar di Propinsi Jawa Barat. [Disertasi] Bogor: Institut Pertanian Bogor. Sekolah Pascasarjana. Halaman 7-75 
Hadi S. 2014. Profil modal sosial dan tingkat partisipasi peternak pada pengembangan sapi potong di Kabupaten Tebo Provinsi Jambi Program Studi Penyuluhan dan Komunikasi Pembangunan Fakultas Perternakan UGM Yogyakarta. Kanal, 2(2): 107-206

Kabupaten Sumedang. 2012. Perda Kabupaten Sumedang No. 2 Tahun 2012 tentang Rencana Tata Ruang dan Rencana Wilayah Kabupaten Sumedang Tahun 2011-2031.

Kustiari T. 2012. Pengaruh efektivitas penyuluhan terhadap kompetensi pembudidaya rumput laut polikultur di Perairan Pantai Utara Pulau Jawa. Jurnal Sosek KP, 7(1): 79-95

Mahbud. 2007. Penyuluhan kehutanan partisipatif. Jurnal Hutan dan Masyarakat 2(3): 313-318.

Muchtar K. 2016. Penerapan komunikasi partisipatif pada pembangunan di Indonesia. Jurnal Makna, 1(1): 20

Nataliningsih. 2010. Dampak penyuluhan pertanian partisipatif terhadap peningkatan kesejahteraan kelompok tani pemula. (studi kasus di Kecamatan Cileunyi, Kabupaten Bandung). e- Jurnal. unbar.ac.id: 2-15 [13 Maret 2016].

Pujiastuti S. 2014. Perkuat peran penyuluh perikanan. Kementerian Kelautan dan Perikanan Ditulis oleh Diah Anggraeni Retnaningrum, Desember 2014 www. satuharapan.com [13 Maret 2016] Safiudin. 2008. Hubungan karakteristik dengan kompetensi pembudidaya rumput laut di Tiga Kabupaten di Provinsi Sulawesi Selatan. [Disertasi] Bogor: Institut Pertanian Bogor, Sekolah Pascasarjana

Safrida. 2015. Peran penyuluh perikanan dalam pengembangan sektor perikanan di Kabupaten Aceh Uta-ra. Jurnal Agrisep, 16(2) tahun 2015.

Sjafari A. 2010. Keberdayaan keluarga miskin di perkotaan dalam meningkatkan kesejahteraannya (Kasus di Kota Jakarta Utara dan Kota Bekasi). [Disertasi] Bogor: Institut Petanian Bogor, Sekolah Pascasarjana. 